\title{
The Arg753GIn polymorphism of the human Toll-like receptor 2 gene in tuberculosis disease
}

\author{
A.C. Ogus*, B. Yoldas", T. Ozdemir*, A. Uguz", S. Olcen", I. Keser ${ }^{+}$, M. Coskun", A. Cilli*, O. Yegin"
}

The Arg753Gln polymorphism of the human Toll-like receptor 2 gene in tuberculosis disease. A.C. Ogus, B. Yoldas, T. Ozdemir, A. Uguz, S. Olcen, I. Keser, M. Coskun, A. Cilli, O. Yegin. (C) ERS Journals Ltd 2004.

ABSTRACT: Toll-like receptor 2 (TLR2), a member of the Toll-like receptor family, plays an important role in recognition of, and subsequent immune response activation against, mycobacteria. The genetic polymorphism of TLR2 (arginine to glutamine substitution at residue 753 (Arg753GIn)) has been associated with a negative influence on TLR2 function, which may, in turn, determine the innate host response to mycobacteria. The aim of the present study was to investigate the Arg753Gln single nucleotide polymorphism of the TLR2 gene in tuberculosis (TB) patients compared to healthy controls.

A retrospective case/control study was carried out. The Arg753GIn polymorphism of the TLR2 gene was studied in 151 TB patients compared to 116 ethnically and agematched healthy control subjects.

The TLR2 polymorphism (adenine (A) allele) was observed in 17.9 and $7.7 \%$ of TB patients and controls, respectively. When the ratios of the three genotypes were compared between the two groups, the AA genotype was found to be more significantly associated with TB. Allele frequencies for guanine (G) and $A$ were found to be 0.95 and 0.05 in the control group and 0.86 and 0.14 in the TB patient group, respectively. The risk of developing TB disease was increased 6.04- and 1.60-fold for carriers of the AA and GA genotypes, respectively.

In conclusion, the present data suggest that the arginine to glutamine substitution at residue 753 polymorphism of the Toll-like receptor 2 gene influences the risk of developing tuberculosis.

Eur Respir J 2004; 23: 219-223.
Depts of *Chest Medicine, ${ }^{\#}$ Paediatric Immunology, and ${ }^{+}$Medical Biology and Genetics, Akdeniz University Medical Faculty, and TState Tuberculosis Control Centre, Antalya, Turkey.

Correspondence: A.C. Ogus

Fener mahallesi

Tekelioglu Caddesi

Sema apt. No: $54 / 5$

07100

Antalya

Turkey

Fax: 902422274490

E-mail: candanogus@akdeniz.edu.tr

Keywords: Immunity

polymorphism

Toll-like receptor

tuberculosis

Received: June 22003

Accepted after revision: August 282003

This study was supported by Akdeniz University Research Foundation, Akdeniz University, Antalya, Turkey (2002.01.0103.008).
Tuberculosis (TB) is still a leading cause of death worldwide, and the incidence of the disease has been reported to have increased since the early 1980s. Almost a third of the world's population is infected with Mycobacterium tuberculosis, whereas only $5-15 \%$ of those who have been infected develop clinical TB disease during their lifetime [1, 2]. The exact reasons as to why only some of the individuals exposed to $M$. tuberculosis develop uncontrolled disease and others eradicate or limit the disease remains unknown. The evidence suggests that genetic factors may be important determinants of increased susceptibility to progressive disease development [3-7]. The immune pathogenesis of the disease involves several components of the immune system, especially including macrophages, T-lymphocytes, tumour necrosis factor- $\alpha$ $(\mathrm{TNF}-\alpha)$ and interferon gamma, which play a major role in the defence mechanisms against this microorganism. Multiple components of the mycobacterium stimulate the macrophages, leading to increased TNF- $\alpha$ production, which, in turn, further activates the macrophages, leading to granuloma formation [8]. Recent data show that multiple components of the mycobacterium also activate the macrophages, mainly through Toll-like receptor (TLR) 2 (TLR2) [8-15].

TLRs comprise a family of mammalian cell-surface proteins that stimulate pro-inflammatory cytokine gene transcription in response to various microbial ligands. TLRs mediate cellular responses to microorganism, but are not required for phagocytosis. Members of the mammalian TLR family have been implicated in the activation of macrophages by a variety of chemically diverse bacterial products $[9,16]$. TLR2 is involved in the recognition of various bacterial lipoproteins, such as peptides derived from Borrelia, Mycoplasma and Treponema, as well as $M$. tuberculosis $[13,17]$. Blocking this receptor abolishes the ability of macrophages to sense and respond to mycobacterial peptides. Macrophages sense the presence of mycobacteria through activation of TLR2 (firstline defence), triggering activation of further immune response (TNF- $\alpha$, interleukin-1 production, antigen processing, activation of T-lymphocytes, interferon gamma production, etc.) in later events. In vitro studies have shown that TLR2 activation directly leads to intracellular killing of $M$. tuberculosis by alveolar macrophages [18].

Single-nucleotide polymorphisms (SNPs) are deoxyribonucleic acid (DNA) sequence variations that occur when a single nucleotide (adenine (A), thymine $(\mathrm{T})$, cytosine $(\mathrm{C})$ or guanine $(\mathrm{G})$ ) in the genome sequence is altered. Many SNPs have no effect on cell function, but some SNPs, especially if they affect the function of the gene, could predispose people to disease or influence their response to a drug [19]. LoRENZ et al. [17] reported a novel polymorphism in the TLR2 gene (arginine to glutamine substitution at residue 753 (Arg753Gln)) that leads to a decreased response of macrophages to bacterial peptides, resulting in an attenuated immune response in the host.

The aim of the present study was to investigate the occurrence of the Arg753Gln polymorphism of the TLR2 
gene in patients with TB disease compared to healthy controls.

\section{Materals and methods}

\section{Study subjects}

The study population consisted of 151 patients with newly diagnosed TB disease who were undergoing TB treatment at the Dept of Chest Medicine, Akdeniz University Medical Faculty, and the State Tuberculosis Control Centre (Antalya, Turkey) during March 2002-March 2003.

The diagnostic criterion for the presence of TB disease was defined as the presence of at least one of the following: 1) clinical and radiological findings consistent with TB disease and positive sputum smears for acid-fast bacilli on at least two separate occasions; 2) culture positivity of sputum, bronchial lavage and/or pleural fluid as well as samples from organ systems other than the lung (urine, semen, cerebrospinal fluid, etc.) for M. tuberculosis; and 3) pathological evidence of TB disease in biopsy materials (lymph node, lung, etc.)

Patients not providing conclusive evidence for the diagnosis of TB disease or who had an additional disease such as acquired immune deficiency syndrome, malnutrition and/or diabetes mellitus were excluded from the study, as well as those from different ethnic backgrounds.

The control group consisted of 116 unrelated subjects from the Dept of Chest Medicine outpatient clinic and renal transplantation donors from the Transplantation Centre (Akdeniz University Medical Faculty) who had been investigated and been found to be healthy. The inclusion criteria for the control group were the absence of acute or chronic pulmonary disease and a negative history for TB disease. All of the controls were from the same ethnic and geographical origin, living in the same city as the TB cases.

Demographic data, including sex and age, and clinical data, including TB localisation, method of diagnosis of TB disease, results of sputum examination and, if available, relapsed TB diagnosis were recorded.

The study was approved by the local ethics committee of the Akdeniz University School of Medicine and written informed consent was obtained from all patients and control subjects.

The Arg753Gln polymorphism of TLR2 was investigated in patients with TB and controls in the Central Research Laboratory of Akdeniz University School of Medicine.

\section{Genotyping of arginine to glutamine substitution at residue 753 polymorphism of Toll-like receptor 2}

Genomic DNA was isolated from peripheral whole blood using the Genomic DNA Purification Kit (MBI Fermentas, St Leon-Rot Germany). Primer sets were designed from the TLR 2 coding sequence (GenBank accession No. 88878) using TLR2 polymorphism detection with amplification refractory mutation system polymerase chain reaction (PCR) at position 2258 of the open reading frame [20]. This polymorphism results in an arginine (CGG) to a glutamine (CAG) substitution and the resulting genotypes, therefore, are arginine/ arginine (GG), glutamine/glutamine (AA) and arginine/glutamine (AG).

The nucleotide sequences of the primers used in the present study are listed in table 1 . PCR was performed with $120 \mathrm{ng}$ extracted DNA, and DNA amplification with 1 U Taq DNA polymerase (MBI Fermentas), $8 \mathrm{mM}$ deoxyribonucleoside
Table 1.-Primers used for detection of polymorphism at position 2258 of the Toll-like receptor 2 (TLR2) gene

\begin{tabular}{lc}
\hline Primer & Nucleotide sequence \\
\hline TLR2-F & TATGGTCCAGGAGCTGGAGA \\
TLR2-R & TGACATAAAGATCCCAACTAGACAA \\
TLR2-G & GGTCTTGGTGTTCATTATCTTCC \\
TLR2-A & GGTCTTGGTGTTCATTATCTTCT
\end{tabular}

T: thymine; A: adenine; G: guanine; C: cytosine.

triphosphates (MBI Fermentas) and 20 pmol each primer. The reaction for the common allele $(G)$, with TLR2-F, TLR2$\mathrm{R}$ and TLR2-G, and then the reaction for the rare allele (A), with TLR2-F, TLR2-R and TLR2-A (TIB MOLBIOL, Berlin, Germany), were performed in a final volume of $50 \mu \mathrm{L}$ under the following conditions: 4 min of initial denaturation at $94^{\circ} \mathrm{C}$, followed by 35 cycles of denaturation for $1 \mathrm{~min}$ at $94^{\circ} \mathrm{C}$, annealing for $1 \mathrm{~min}$ at $62^{\circ} \mathrm{C}$ and extension for $1 \mathrm{~min}$ at $72^{\circ} \mathrm{C}$, with variation in the annealing temperature. Final extension was carried out for $4 \mathrm{~min}$ at $72^{\circ} \mathrm{C}$. Amplification was carried out in a Genius PCR System (Techne, Cambridge, UK).

PCR products were subjected to electrophoresis in a $2 \%$ agarose gel and stained with ethidium bromide. The 470-base pair (bp) PCR product was amplified using TLR2-F and TLR2-R, and the 328-bp product using TLR2-A and TLR2-F, or TLR2-G and TLR2-F.

A p-value of $<0.05$ was accepted as significant. Chi-squared tests were used for the comparison of allele and genotype distribution in the study groups. The Hardy-Weinberg equilibrium was assessed using Haldane's exact test [21].

\section{Results}

Of the 151 study patients, $52(34.4 \%)$ were female and 99 $(65.6 \%)$ male. Their mean \pm SD age was $35.4 \pm 13.5$ yrs. All of the patients and controls were ethnically of Turkish origin and living in Antalya city and its provinces. During the first 3 months, $121(80.1 \%)$ cases from the State Tuberculosis Control Centre were sampled, whereas the rest of the patient samples were collected from the Dept of Chest Medicine, Akdeniz University Medical Faculty, throughout the study period.

Pulmonary TB was diagnosed in $129(85.4 \%)$ cases, TB lymphadenitis in eight $(5.3 \%)$ and pleural TB in $10(6.6 \%)$. One patient $(0.7 \%)$ had TB infection of the bone and another $(0.7 \%)$ renal TB. Two patients $(1.3 \%)$ had both pulmonary TB and TB lymphadenitis (table 2).

TB diagnosis was determined by sputum or bronchial lavage smear positivity in $20(13.2 \%)$ cases, by sputum, bronchial lavage or pleural fluid culture positivity in 111

Table 2. - Toll-like receptor 2 genotypes and clinical types of tuberculosis (TB) disease

\begin{tabular}{lcccc}
\hline \multirow{2}{*}{ Type of TB } & Subjects & \multicolumn{3}{c}{ Genotype } \\
\cline { 3 - 5 } & $\mathrm{n}(\%)$ & AA n & GA n & GG n \\
& & & & \\
\hline Pulmonary & $129(85.4)$ & 11 & 12 & 106 \\
Lymphadenitis & $8(5.3)$ & 2 & 1 & 5 \\
Pleural & $10(6.6)$ & & & 10 \\
Pulmonary and lymphadenitis & $2(1.3)$ & 1 & & 1 \\
Bone & $1(0.7)$ & & & 1 \\
Renal & $1(0.7)$ & & & 1
\end{tabular}

A: adenine; G: guanine. 
$(73.5 \%)$ cases and by pathological examination of biopsy material in $22(14.5 \%)$ cases. Two cases with pulmonary tuberculosis and lymphadenitis were determined by sputum culture positivity and biopsy. A diagnosis of relapsed TB was made in seven $(4.6 \%)$ cases.

The control group consisted of $53(45.7 \%)$ males and 63 $(54.3 \%)$ females with a mean \pm SD age of $35.9 \pm 14.8$ yrs. Twenty five $(21.5 \%)$ of the control subjects were from the Dept of Chest Medicine outpatient clinic, whereas the rest were healthy organ donors for transplantation from the Transplantation Centre. Blood sample were not taken from more than one individual from each family.

The genotype distribution in the group of patients with TB disease is given in table 2. The TLR2 Arg753Gln polymorphism A allele occurred in $27(17.9 \%)$ of the $151 \mathrm{~TB}$ patients (fig. 1), whereas homozygous carriers of the A/A allele polymorphism comprised $14(9.3 \%)$ of the TB patients. The TLR2 Arg753Gln A allele occurred in nine (7.7\%) subjects in the control group, whereas two $(1.7 \%)$ were homozygous carriers of this polymorphism. The study and control groups were not in Hardy-Weinberg equilibrium. Hardy-Weinberg exact test p-values were 0.000 and 0.017 for the study and control groups, respectively. The deviation in the control group may possibly be related to the inclusion of one extra AA subject, since there would have been no deviation had there been one rather than two subjects of this genotype, i.e. deviation was minimal. When a Chi-squared test was performed for evaluation of the differences in the ratios of the three genotypes between the two groups, the AA genotype was found to be more significantly associated with TB than the GA and GG genotypes $(\mathrm{p}=0.022)$ (table 3 ). Allele frequencies for $\mathrm{G}$ and $\mathrm{A}$ were found to be 0.95 and 0.05 in the control group and 0.86 and 0.14 in the patient group, respectively. The odds ratios for the AA and GA genotypes for predisposing to TB were found to be 6.04 (95\% confidence interval (CI) 2.01-20.08) and 1.60 (1.01-2.55), respectively, in the patients.

No significant correlation was detected between the TLR2 polymorphism and TB disease localisation $(\mathrm{p}>0.05)$. However,
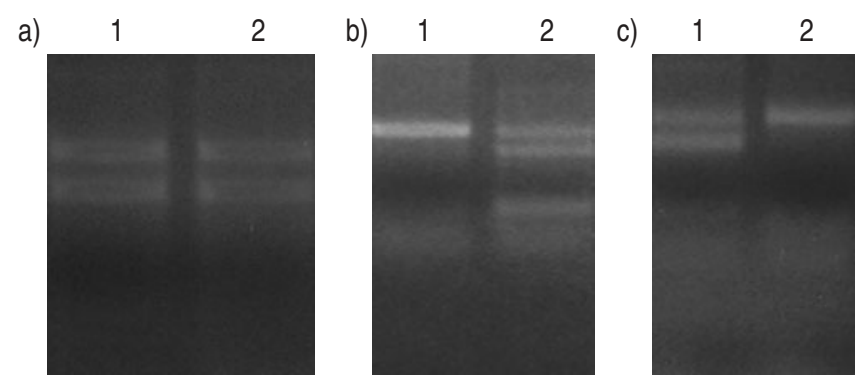

Fig. 1.- Typical amplification refractory mutation system polymerase chain reaction (PCR) analysis results for: a) GA (heterozygous carrier of polymorphism); b) AA (homozygous carrier of polymorphism); and c) GG (normal) genotype. The upper bands represent the 470base pair internal control PCR fragment and the lower bands the $G$ (lane 1) and A (lane 2) alleles. one of the two cases of pulmonary TB plus lymphadenitis was a homozygous carrier of the rare variant (table 2). Furthermore, in four of the seven cases with relapsed TB, one was homozygous and three were heterozygous carriers of the TLR2 polymorphism.

Since each form of TB may also be considered a different phenotype, further analysis was performed only in patients with pulmonary TB. The pulmonary TB group consisted of 88 $(68.2 \%)$ males and $41(31.8 \%)$ females with a mean \pm SD age of $35.6 \pm 13.6$ yrs. The allelic frequency for A was $17.8(n=23)$ versus $7.7 \%(\mathrm{n}=9)$ in patients with pulmonary $\mathrm{TB}$ and healthy controls, respectively, whereas the homozygous (AA) genotype was detected in $11(8.5 \%)$ pulmonary TB patients and two $(1.7 \%)$ controls. When a Chi-squared test was performed for evaluation of the differences in the ratios of the three genotypes between the two groups, the AA genotype was found to be more significantly associated with TB than the GA and GG genotypes ( $\mathrm{p}=0.019)$ (table 3 ). Allele frequencies for $\mathrm{G}$ and $\mathrm{A}$ were found to be 0.87 and 0.13 in the pulmonary TB group and 0.95 and 0.05 in the control group, respectively. The odds ratios for the AA and GA genotypes for predisposing to TB were 5.55 (95\% CI 1.68-18.34) and 1.73 (1.07-2.80) in the pulmonary TB group, respectively.

\section{Discussion}

In the present report, a significant difference was found between patients with TB disease and healthy controls in both TLR2 Arg753Gln polymorphism genotype and allelic distribution. Furthermore, it was found that the allelic frequency of the TLR2 Arg753Gln polymorphism gene (A allele) was $4.7 \%(1.7 \%$ homozygous and $6 \%$ heterozygous $)$ in healthy Turkish controls. LORENZ et al. [17] reported this mutation in $3 \%$ of their population. Further data are needed to determine whether the polymorphic TLR2 gene shows an ethnically varying distribution.

The present data clearly show that, in the patient group, the frequency of the homozygous AA genotype was significantly higher than in healthy controls, and this difference remained significant even when patients with pulmonary TB alone were taken into account (table 3). The present data also suggest that the risk of developing TB disease in subjects with the AA and GA genotype of the TLR2 polymorphism is 6.04- and 1.60 -fold higher, respectively, than in carriers of the GG genotype. To the present authors' knowledge, this is the first report showing an association between TLR2 gene polymorphism and the occurrence of TB disease.

It has previously been demonstrated that the TLR 2 polymorphism results in a decrease in the ability of macrophages to respond to several bacterial peptides [17]. KANG and CHAE [22] studied a different, arginine to typtophan substitution at residue 677 , polymorphism of the TLR 2 gene in patients with leprosy and found a strong association between the occurrence of the polymorphism and lepromatous but not tuberculoid leprosy. This finding suggests a role of the TLR 2 gene

Table 3.-Distribution of the Toll-like receptor 2 polymorphism and odds ratios in the study and control groups

\begin{tabular}{lcccccccc}
\hline Genotype & Controls n (\%) & \multicolumn{3}{c}{ Study group } & & \multicolumn{3}{c}{ Pulmonary TB } \\
\cline { 3 - 6 } & & Subjects n (\%) & $\mathrm{X}^{2}$ & Odds ratio (95\% CI) & & Subjects n (\%) & $\mathrm{X}^{2}$ & Odds ratio (95\% CI) \\
\hline AA & $2(1.7)$ & $14(9.3)$ & $6.35^{\#}$ & $6.04(2.01-20.08)$ & & $11(8.5)$ & 5.96 & $5.55(1.68-18.34)$ \\
GA & $7(6)$ & $13(8.6)$ & 0.59 & $1.60(1.01-2.55)$ & & $12(9.3)$ & 1.21 & $1.73(1.07-2.80)$ \\
GG & $107(92.3)$ & $124(82.1)$ & 0.77 & - & & $106(82.2)$ & 0.81 & - \\
Total & $116(100)$ & $151(100)$ & - & - & & $129(100)$ & - & - \\
\hline
\end{tabular}

TB: tuberculosis; CI: confidence interval; A: adenine; G: guanine. ${ }^{\#}$ : $\mathrm{p}=0.022 ;{ }^{\top}: \mathrm{p}=0.019$. 
and its polymorphisms in disease susceptibility, possibly through impaired first-line defence mechanisms.

BocHUD et al. [23] showed that polymorphism of the TLR2 gene caused severe impairment of the macrophage response to $M$. leprae and $M$. tuberculosis. It was also shown that a mutation in mouse TLR2 (TLR2-P681H) acts as a dominant negative inhibitor of TLR2 signalling, and expression of this mutation in the RAW cell line inhibited tumour necrosis factor induction in response to both virulent and avirulent $M$. tuberculosis [22]. REILING et al. [10] studied resistance to airborne infection with $M$. tuberculosis in TLR2, TLR4 and CD14 knockout and control mice groups and found that TLR2 knockout mice showed decreased resistance to TB on high-dose exposure, but no difference between the groups was observed under natural low-dose airborne infection conditions. These data suggest that carrying a defective TLR2 gene could be a causative factor for increased susceptibility to progressive TB disease. However, there is no direct evidence that this polymorphism causes a decrease in immune response specifically to $M$. tuberculosis. Despite the significance between patients and healthy controls, the TLR2 polymorphism is present only in a small subset $(17.9 \%)$ of patients with TB disease. Therefore, TLR2 gene polymorphism may be one of the factors influencing disease susceptibility, and other factors or defects in different steps of the immune response (even other polymorphisms of TLR2 or other TLRs) might also be responsible for an inability to prevent progression of TB infection to disease. It has been already shown that those individuals with interferon gamma receptor, IL-12 or IL-12 receptor deficiency or signal transducer and activator of transcription 1 mutation show increased susceptibility to mycobacterial infections [7, 24-26]. Data from other studies suggest that SNPs of natural resistance-associated macrophage protein 1 (solute carrier family 11 , member 1 ) and vitamin $\mathrm{D}$ receptor genes contribute to human susceptibility to TB [27-29].

In the present study, all consecutive cases of TB disease were included, but the majority were patients with pulmonary TB. It was not possible to demonstrate an association between the system involved and TLR2 polymorphism. However, the paucity of cases with extrapulmonary TB limits statistical analysis of these data for a possible association between organ preference and host TLR2 allele (table 2). It is of note, however, that the GA (three cases) and AA (one case) genotypes were present in four of seven of the relapse cases, whereas the homozygous AA genotype was detected in one patient with pulmonary TB and lymphadenitis. The present authors are, therefore, of the opinion that larger series are needed to test for a possible association between TLR2 gene polymorphism and organ preference, as well as clinical severity of disease.

Turkey is a country with a moderate TB incidence, reaching 33.7 per 100,000 population in 1999 and 26.3 per 100,000 in 2000 [30, 31]. Under these circumstances, all children are routinely vaccinated with bacille Calmette-Guérin (BCG) vaccine soon after birth in Turkey. BCG vaccination policy, which consisted of four administrations (at 2 months and 5, 12 and $17 \mathrm{yrs}$ ) until 1998, has since been changed to three administrations (at 2 months and 5 and $12 \mathrm{yrs}$ ). The tuberculin skin test (TST), therefore, has a high positivity rate in Turkey and a positive TST does not differentiate conclusively between exposure due to contact or BCG vaccination. In the Turkish population, the chance of obtaining a control group with a negative TST is practically impossible and, therefore, a TST was not performed in the control group to exclude TB disease.

The deviation from the Hardy-Weinberg equilibrium in the case group could be caused by true genetic association. Considering the possible reasons for the deviation from the
Hardy-Weinberg equilibrium encountered in the control group, since genotyping for both patient and control groups was performed simultaneously by the same laboratory technician in the same laboratory, it is thought that the genotyping error rate is minimal. During formation of the study group, only one subject per family was included, to avoid the possibility of including close relatives. However, it was not possible to assess the occurrence of in-family marriages among the subjects. Consanguineous marriages are still very common in Turkey and the total consanguinity rate was found to be $35.2 \%, 39.6$ and $28.3 \%$ for rural and urban areas, respectively, in Antalya in 1989 [32]. Thus, inbreeding could have contributed to the slight deviation from the HardyWeinberg equilibrium that was observed in the control population. Since both control and case populations were selected from the same source population, it is contended that the observed SNP association with TB probably relates to a direct functional effect of this polymorphism or linkage disequilibrium with another functional variant.

In conclusion, the arginine to glutamine substitution at residue 753 polymorphism of the Toll-like receptor 2 gene is another candidate gene that may have an influence on increased susceptibility to the development and severity of tuberculosis disease and further and larger studies are needed to clarify this issue.

\footnotetext{
Acknowledgements. The authors would like to thank H. Gulkesen for statistical analysis and F. Gunseren for constructive criticism. The authors are also thankful to N. Meric, G. Bilginer, E. Yegin, Z. Savc and G. Taner (State Tuberculosis Control Centre, Antalya, Turkey) for providing tuberculosis patients and E. Toprak for technical assistance.
}

\section{References}

1. Rosman MD, Oner Eyüpoğlu AF. Clinical presentation and treatment of tuberculosis. In: Fishman AP, ed. Fishman's Pulmonary Diseases and Disorders. 3rd Edn. New York, NY, USA, McGraw-Hill, 1998; pp. 2483-2501.

2. Fraser RS, Muller NL, Colman N, Pare PD. eds. Mycobacteria. In: Fraser and Pare's Diagnosis of Diseases of the Chest. 4th Edn. Philadelphia, PA, USA, W.B. Saunders Company, 1999; pp. 798-873.

3. Newport MJ, Huxley CM, Huston S, et al. A mutation in the interferon- $\gamma$-receptor gene and susceptibility to mycobacterial infection. N Engl J Med 1996; 335: 1941-1949.

4. Jouanguy E, Lamhamedi S, Emile JF, et al. Interferon- $\gamma-$ receptor deficiency in an infant with fatal bacilli CalmetteGuérin infection. N Engl J Med 1996; 335: 1956-1959.

5. Casanova JL, Abel L. Genetic dissection of immunity to mycobacteria: the human model. Annu Rev Immunol 2002; 20: 581-620.

6. Guide SV, Holland SM. Host susceptibility factors in mycobacterial infection. Genetics and body morphotype. Infect Dis Clin North Am 2002; 16: 163-186.

7. Dupuis S, Dargemont C, Fieschi C, et al. Impairment of mycobacterial but not viral immunity by a germline human STAT1 mutation. Science 2001; 293: 300-303.

8. Crevel R, Ottenhoff THM, Meer WM. Innate immunity to Mycobacterium tuberculosis. Clin Microbiol Rev 2002; 15: 294-309.

9. Means TK, Jones BW, Schromm AB, et al. Differential effects of a Toll-like receptor antagonist on Mycobacterium tuberculosis-induced macrophage responses. J Immunol 2001; 166: 4074-4082.

10. Reiling N, Hölscher C, Fehrenbach A, et al. Cutting edge: 
Toll-like receptor (TLR) 2- and TLR4-mediated pathogen recognition in resistance to airborne infection with $\mathrm{Myco-}$ bacterium tuberculosis. J Immunol 2002; 169: 3480-3484.

11. Bulut Y, Faure E, Thomas L, Equils O, Arditi M. Cooperation of Toll-like receptor 2 and 6 for cellular activation by soluble tuberculosis factor and Borrelia burgdorferi outer surface protein A lipoprotein: role of Toll-interacting protein and IL-1 receptor signaling molecules in Toll-like receptor 2 signaling. $J$ Immunol 2001; 167: 987-994.

12. Tsuji S, Matsumoto M, Takeuchi $\mathrm{O}$, et al. Maturation of human dendritic cells by cell wall skeleton of Mycobacterium bovis bacillus Calmette-Guérin: involvement of Toll-like receptors. Infect Immun 2000; 68: 6883-6890.

13. Means TK, Wang S, Lien E, Yoshimura A, Golenbock DT, Fenton MJ. Human toll-like receptors mediate cellular activation by Mycobacterium tuberculosis. J Immunol 1999; 163: 3920-3927.

14. Noss EH, Pai RK, Sellati TJ, et al. Toll-like receptor 2-dependent inhibition of macrophage class II MHC expression and antigen processing by $19-\mathrm{kDa}$ lipoprotein of Mycobacterium tuberculosis. J Immunol 2001; 167: 910-918.

15. Ozinsky A, Underhill DM, Fontenot JD, et al. The repertoire for pattern recognition of pathogens by the innate immune system is defined by cooperation between Toll-like receptors. Proc Natl Acad Sci USA 2000; 97: 1376613771

16. Supajatura V, Ushio $\mathrm{H}$, Nakao A, et al. Differential responses of mast cell Toll-like receptors 2 and 4 in allergy and innate immunity. $J$ Clin Invest 2002; 109: 1351-1359.

17. Lorenz E, Mira JP, Cornish KL, Arbour NC, Schwartz DA. A novel polymorphism in the Toll-like receptor 2 gene and its potential association with staphylococcal infection. Infect Immun 2000; 68: 6398-6401.

18. Thoma-Uszynski S, Stenger S, Takeuchi O, et al. Induction of direct antimicrobial activity through mammalian Toll-like receptors. Science 2001; 291: 1544-1547.

19. Sachidanandam R, Weissman D, Schmidt SC, et al. A map of human genome sequence variation containing 1.42 million single nucleotide polymorphisms. Nature 2001; 409: 928-933.

20. Newton CR, Graham A, Heptinstall LE, et al. Analysis of any point mutation in DNA. The amplification refractory mutation system (ARMS). Nucleic Acids Res 1989; 17: 2503-2516.
21. Weiss ST, Martinez F. Bioinformatics Tools. Exact HardyWeinberg. http://innateimmunity.net/IIPGA2/Bioinformatics/ Date updated: 4 August 2003. Date accessed: August 2003.

22. Kang TJ, Chae GT. Detection of Toll-like receptor 2 (TLR2) mutation in the lepromatous leprosy patients. FEMS Immunol Med Microbiol 2001; 31: 53-58.

23. Bochud PY, Hawn TR, Aderem A. Cutting edge: a Toll-like receptor 2 polymorphism that is associated with lepromatous leprosy is unable to mediate mycobacterial signalling. J Immunol 2003; 170: 3451-3454.

24. Frucht DM, Holland SM. Defective monocyte costimulation for IFN- $\gamma$ production in familial disseminated Mycobacterium avium complex infection: abnormal IL-12 regulation. J Immunol 1996; 157: 411-416.

25. de Jong R, Altare F, Haagen IA, et al. Severe mycobacterial and Salmonella infections in interleukin-12 receptor-deficient patients. Science 1998; 280: 1435-1438.

26. Dorman SE, Holland SM. Mutation in the signal-transducing chain of the interferon-gamma receptor and susceptibility to mycobacterial infection. J Clin Invest 1998; 101: 2364 2369.

27. Bellamy R, Ruwende C, Corrah T, McAdam K, Whittle HC, Hill AVS. Variations in the NRAMP1 gene and susceptibility to tuberculosis in West Africans. N Engl J Med 1998; 338: 640-644.

28. Awomoyi AA, Marchant A, Howson JMM, McAdam KPWJ, Blackwell JM, Newport MJ. Interleukin-10, polymorphism in SCL11A1 (formerly NRAMP1), and susceptibility to tuberculosis. J Infect Dis 2002; 186: 1808-1814.

29. Bellamy R, Ruwende C, Corrah T, et al. Tuberculosis and chronic hepatitis $\mathrm{B}$ virus infection in Africans and variation in the vitamin D receptor gene. J Infect Dis 1999; 179: 721724.

30. Ozkara S, Kilicaslan Z, Ozturk F, et al. Bolge verileriyle Turkiye'de tuberkuloz. Toraks Dergisi 2002; 3: 178-187.

31. Cuhadaroglu C, Erelel M, Tabak L, Kilicaslan Z. Increased risk of tuberculosis in health care workers: a retrospective survey at a teaching hospital in Istanbul, Turkey. BMC Infect Dis 2002; 2: 14. http://www. biomedcentral.com/14712334/2/14

32. Guz K, Dedeoglu N, Luleci G. The frequency and medical effects of consanguineous marriages in Antalya, Turkey. Hereditas 1989; 111: 78-83. 